\title{
Perfil dos usuários de crack na mídia brasileira: análise de um jornal e duas revistas de edição nacional
}

| ${ }^{1}$ Daniele Farina Zanotto, ${ }^{2}$ Fátima Büchele Assis |

Resumo: Este artigo é uma pesquisa documental com abordagem qualitativa, resultado de uma tese de doutorado, que buscou analisar o perfil dos usuários de crack apresentado por reportagens de um jornal e duas revistas de edição nacional, nos últimos cinco anos. $\mathrm{O}$ material encontrado foi submetido à análise textual discursiva. Para acessar o objeto de estudo, nossa base teórica contou com os autores Michel Foucault, Erwin Goffman, Howard Becker e John Thompson, buscando desnaturalizar as maneiras como os discursos sobre os usuários de crack são colocados pela mídia. Os resultados evidenciaram que o discurso veiculado pelos meios de comunicação estudados constrói no senso comum um perfil negativo sobre o usuário de crack, permeado por preconceito e estigma. As reportagens são transmitidas de forma sensacionalista e higienista, dando ênfase ao enfrentamento aos usuários e não somente à droga em si. Conclui que o discurso apresentado é capaz de materializar as representaçôes da classe dominante sobre os usuários de crack e de refletir na forma em que a sociedade convive com eles. Entende-se como classe dominante aquela representada pelo modelo biomédico de cuidado em saúde mental.

> Palavras-chave: usuários de crack; mídia; reforma psiquiátrica brasileira.

\footnotetext{
1 Saúde Coletiva, Universidade Federal de Santa Catarina. Florianópolis-SC, Brasil

(danitifarina@yahoo.com.br).

2 Saúde Coletiva, Universidade Federal de Santa Catarina.

Florianópolis-SC, Brasil (fbuchele79@gmail.com).
}

Recebido em: 19/08/2016 Aprovado em: 21/01/2017 


\section{Introdução}

Após quinze anos da promulgação da Lei n. 10.216/2001, que dispóe sobre a proteção e os direitos das pessoas portadoras de transtornos mentais e redireciona o modelo assistencial em saúde mental no Brasil, a rede de atenção substitutiva ainda não foi suficiente para garantir a reestruturação e o cuidado em saúde mental em geral e em particular aos usuários de crack em sua plenitude.

Essa Lei foi resultado do processo de lutas e marco legal da Reforma Psiquiátrica Brasileira. Mesmo após debates e avanços no campo da saúde mental, a mídia permeada por suas relações políticas e comerciais vem retomando discursos higienistas ante estes indivíduos. Isso é visto pelo modo amedrontador como aborda o assunto em suas reportagens e noticiário, destacando a limpeza social, a internação compulsória e conteúdos regados por denominaçóes pejorativas. Essa prática legitima repulsa da sociedade perante os usuários.

Nos últimos anos, essas questôes ganharam mais espaço, principalmente nas páginas policiais de jornais impressos ou em reportagens de telejornais, alimentando no imaginário coletivo os possíveis "males" que estes indivíduos podem vivenciar e provocar outros.

Segundo Arenari e Dutra (2016), os usuários de crack são o alvo da histeria social e da construção de estigmas, eles são a parte visível para a sociedade do consumo das drogas, justamente a parte deste comportamento que não é tolerado por ela. O argumento central apresentado pelos autores parte do pressuposto de que um dos problemas sociais mais frequentes é a exclusão social. Geralmente é demonstrado pela mídia levando à formação de um tipo de identidade marcada pela participação precária na maioria das esferas sociais e no limite à negação do status de pessoa aos indivíduos.

Então, considerando que a imagem do usuário de crack não resulta necessariamente de si só, mas é produto dos que o enxergam (ou o ignoram), e considerando também que é fruto de uma variedade de instituiçôes que os interpretam, entre elas a mídia, movida pela ideologia da classe dominante, faz sentido que estes meios lhes atribuam expectativas de conduta específicas que acabam confirmando o sentido de exclusão preexistente, como se fosse um ciclo.

A forma como a mídia apresenta o perfil do usuário de crack reproduz um modelo de exclusão já existente, mantém a centralização do poder na instituição 
hospitalar e no modelo biomédico e não insere o indivíduo na comunidade e isso parece vir na contramão da Reforma Psiquiátrica.

Sendo assim, este estudo buscou analisar o perfil dos usuários de crack por meio de reportagens de um jornal e de duas revistas de circulação nacional.

Utilizamos como base teórica autores que respaldaram nossa proposta. Devido à amplitude e complexidade do tema, foram utilizados Michel Foucault, Erwin Goffman, John Thompson e Howard Becker. Dessa forma, suas contribuições serão descritas no decorrer dos resultados.

\section{Método}

Trata-se de uma pesquisa documental com abordagem qualitativa que utilizou o termo de busca "Usuários de Crack". Foram incluídas nela reportagens, opinião do leitor e notas, entre janeiro de 2009 e julho de 2015 em um jornal e duas revistas de circulação nacional com acesso disponível on-line. As buscas ocorreram nas seguintes fontes: jornal Folha de São Paulo, revista Carta Capital e revista Caros Amigos.

A escolha por estas fontes foi baseada na expectativa de encontrar opiniōes distintas e abrangentes sobre o tema, em virtude das características diferentes de cada publicação, entre elas: público-alvo, volume e tipo de publicações (diário, semanal, mensal), objetivos das fontes, tamanho e formato das reportagens. $\mathrm{O}$ que possibilitou reflexōes sobre as discrepâncias e uniformidades de veiculação desta mídia sobre o assunto abordado.

Para coleta dos dados, foram acessados os sites: na revista Carta Capital, o endereço eletrônico utilizado foi: www.cartacapital.com.br. Para à Folha de São Paulo, o site www.folha.uol.com.br e para à revista Caros Amigos, www. carosamigos.com.br. Após o acesso para coleta de dados, os textos foram selecionados a partir da leitura do título da reportagem, sua manchete e seu conteúdo, levando em consideração o assunto principal do texto. Portanto, o critério de inclusão considerou elegíveis aqueles que tinham como tema central usuários de crack. Durante este processo, foram excluídas as reportagens citadas como: notícias em duplicidade; anúncios de eventos (filmes, livros), bem como as que não se encaixaram nos critérios de inclusão.

A etapa analítica seguiu o processo proposto por Moraes e Galiazzi (2007) denominado "analise textual discursiva". Trata-se de uma metodologia de análise 
de dados e informações de natureza qualitativa que busca novas compreensões sobre os fenômenos e discursos. A análise textual discursiva faz parte de um conjunto de métodos compreensivos, com caráter essencialmente hermenêutico, seguindo uma tentativa de valorizar novas concepções que destacam o qualitativo, o sujeito e a superação da objetividade.

Para estes autores, ela pode ser realizada da seguinte forma:

Processo de desconstrução, seguido de reconstrução, de um conjunto de materiais linguísticos e discursivos, produzindo-se a partir disso novos entendimentos sobre os fenômenos e discursos investigados. Envolve identificar e isolar enunciados dos materiais submetidos à análise, categorizar esses enunciados e produzir textos, integrando nestes descrição e interpretação, utilizando como base de sua construção o sistema de categorias construído (ibidem, 2007 p. 112).

O "corpus" foi examinado e analisado pelos pesquisadores a partir dos referenciais teóricos explícitos no marco teórico e à luz de seus conhecimentos, por meio de uma leitura exaustiva, aprofundada e rigorosa. A partir daí, surgiram as categorias emergentes dos textos.

A última fase foi a análise final dos discursos e a transformação das categorias em metatextos, encontrando seus significados pertinentes à pesquisa. Estas categorias estarão representadas a seguir, em meio à análise final destes discursos, encontrando seus significados e contextualizando-as com a literatura referente à Reforma Psiquiátrica Brasileira.

Por se tratar de uma pesquisa documental, em fontes de livre circulação e domínio público, dispensou a submissão ao comitê de ética.

\section{Resultados e Discussão}

O levantamento realizado resultou, no primeiro momento, em 415 reportagens ao total. Foram excluídas 225, por não tratarem do tema como foco central ou aparecerem em duplicidade. Restaram para análise, 190 reportagens, conforme mostra a tabela 1 .

A análise textual discursiva nos permitiu encontrar significados em conteúdos que estavam explícitos e identificáveis nos textos, em contrapartida, outros se encontravam ocultos em meio às frases. Dessa forma, foi possível transformá-los por meio do nosso referencial teórico. 


\begin{tabular}{lccc}
\multicolumn{1}{c}{ FONTE } & RESULTADO & INCLUÍDOS & EXCLUÍDOS \\
\hline FOLHA DE SÃO PAULO & 353 & 162 & 191 \\
CARTA CAPITAL & 43 & 21 & 22 \\
CAROS AMIGOS & 19 & 07 & 12 \\
TOTAL & 415 & 190 & 225 \\
\hline
\end{tabular}

A partir da análise dos textos de Foucault na História da loucura na Idade Clássica (2010), em que o autor desvenda a prática de enclausuramento do louco e suas relaçôes com a psiquiatria, foi possível compreender como ocorreu a transformação da loucura em doença mental e também como se revelou o conceito que temos deste tema na atualidade. Dessa forma, procuramos unir reflexões históricas e conceituais com a realidade atual.

A dependência química ao nosso olhar é tratada da mesma forma à qual a loucura fora denominada pelo autor, como culpa de caráter moral. Unindo isso às ligações feitas da droga crack com o crime e a periculosidade, ou seja, uma figura de ameaça social. Isso justifica a necessidade de exclusão dos usuários em instituições, trazendo repulsa da sociedade tal qual como a loucura causou e desencadeou mecanismos biopolíticos.

Também foi possível, em nossa análise, fazer uma analogia com o que pensa Goffman (1985), pois entendemos que a sociedade usa as informações que tem a respeito dos usuários de crack para definir a situação e tornar possível conhecer antecipadamente o que esperar destes sujeitos. A partir de sua conduta, aparência e experiências prévias com indivíduos idênticos, a sociedade julga ser possível prever seu comportamento, ou, até mesmo, aplicar-lhes estereótipos.

Quando falamos de padrões morais e seus desvios, Becker (2008) refere o processo de imposição e transgressão de regras, porque algumas pessoas as criam e outras as infringem. Nesse caso, o usuário de crack pode ser visto como desviante das normas propostas, pois, ao usar a droga, submete-se a valores incompatíveis com os ditos normais.

Para complementar o eixo teórico, e situar melhor a mídia nesse contexto, Thompson (2002) nos ajudou a considerar os meios de comunicação instrumento 
de profunda influência na formação do pensamento político e social. Isso aparece em nosso estudo de forma muito evidente a partir das categorias abaixo propostas.

\section{Categoria 1: Imagem do usuário de crack}

As reportagens estudadas demonstraram uma imagem sem distinção de gênero ou idade, ou seja: homens, mulheres crianças e adolescentes (Folha de SP, 10/03/13). O gênero mais vulnerável é o feminino (ibidem, 08/09/14; 11/03/14; 19/09/13), pois sofre com consequências físicas, violência sexual e gestações indesejadas, por desconhecerem ou por não terem acesso a medidas preventivas (ibidem, 22/09/13).

Os demais usuários (homens, crianças e idosos) também são abordados de maneira negativa e simplista. Possuem baixo nível sociocultural e educacional e a vida em condições precárias de alimentação e higiene é mostrada como uma simples escolha destes indivíduos, sem qualquer contextualização social, política, ou de saúde (ibidem, 19/01/14; 06/01/12; 14/09/10; 09/08/09).

Esta forma de abordagem mostra ao leitor, ou evidencia, que essas pessoas escolhem as ruas por terem vida fácil neste local, desprezando as condiçóes socioeconômicas precárias e o contexto familiar instável preexistente como a razão do abuso de substâncias.

Este dado visualizado nos textos vai na contramão dos marcadores de exclusão social, aferidos por investigaçôes epidemiológicas. Eles destacam a baixa escolaridade e a cor da pele nesse contexto, sugerindo uma trajetória de marginalização social que precede o uso de drogas. Somam-se a isso, outros marcadores, como a falta de moradia e o desemprego ou trabalho precário (MESSAS et al., 2016).

Quanto à imagem física e corporal, as reportagens definem os usuários com "silhuetas afinadas", pessoas com "feridas e cicatrizes nos braços e pernas" (Folha de SP, 11/03/14), normalmente sujas com "crostas de sujeira nos pés e nas mãos", e condição dentária precária (ibidem, 19/01/2014), retratando os estigmas de Goffman (2004) e tornando o individuo inapto para a aceitação social plena, conforme os ditos do autor.

Quanto à ocupação, os textos dizem que os frequentadores da cracolândia vivem na rua, trabalham fazendo "bicos", recolhem material para revender, guardam carros ou são prostitutas (Folha de SP, 15/01/12). Desconsideram o uso 
controlado do crack, no qual indivíduos consomem a substância, mas mantêm

relações familiares e de trabalho (OLIVEIRA; NAPPO, 2008), como se a única possibilidade a partir do uso fosse ser dependente e viver em condições precárias.

As reportagens também subestimam os atores que alimentam impressões de terem motivos ideais para assumir os papeis que estão representando, ou seja, usuários que o desejam ser. Condutas tidas como impróprias ao padrão idealmente proposto são julgadas e combatidas (GOFFMAN, 1985).

Esse perfil traçado pela mídia tem consequências para a participação social e autoimagem do indivíduo. Segundo Becker (2008), o status desviante é o principal. Este perfil pode mudar sua identidade pública, conferindo a ele outro status. O usuário de crack nesse contexto é rotulado e tratado como tal. Não importa que outra atividade tenha, esta será destacada. Será denominado como tal, e isso irá sobrepor qualquer outro tipo de identificação.

Com esta forma de apresentá-lo, as reportagens esquecem que o uso de drogas está presente em todos os gêneros e extratos sociais e não apenas na figura do usuário homem, negro e pobre. Com essa informação, fica evidente a forma como o nosso sistema criminaliza as populações vulneráveis (GORGULHO, 2006).

\section{Categoria 2: Denominações pejorativas}

Esta categoria mostrou no decorrer das leituras das reportagens os termos pejorativos e estigmatizantes citados como referência aos usuários, revelando a atrocidade e a moral presentes na sociedade, onde estes indivíduos/pessoas são considerados e de certa forma representados desiguais. Estas são as nomenclaturas encontradas: "nóias", "magrinhos com aparência de quem consome drogas", "negros", “descabelados", “desdentados e sujos", "viciados”, “drogados”, "zumbis”, "craqueiros", "reféns do crack", "farrapos humanos", "sem vergonha", "andarilhos", "maltrapilhos", "gente diferenciada", "marginais" e "sacizeiros" (CARTA CAPITAL, 2015; CAROS AMIGOS, 2015; FOLHA DE SP, 2015).

Essas falas publicadas nas reportagens reiteram e fortalecem a convicção dos leitores de que o usuário de crack faz parte de uma "classe" diferente de pessoas. Goffman (1985) afirma que normalmente as pessoas são o que aparentam ser, todavia, as aparências podem ser manipuladas, nesse caso, pela forma como as reportagens as ilustram. Mostra-se, ou se escreve o que quer mostrar, ou evidenciar, e assim cria-se a verdade de que os usuários de crack, por exemplo, 
não possuem um modelo de conduta apropriada, coerente, adequada aos valores morais da sociedade.

Entre os termos acima ilustrados, o mais frequentemente encontrado foi "viciado". Viciado é uma denominação por muito tempo utilizada para identificar os indivíduos que consomem substâncias psicoativas de forma abusiva. Esse termo rotula o usuário, estigmatiza, deprecia alguém que está fadado àquela condição, que privilegia a droga acima de todas as coisas, denotando culpa de caráter moral (GOFFMAN, 2004). O termo "usuário", hoje em dia, é mais utilizado, pois denomina o consumidor, que não necessariamente é dependente da substância e não infere julgamento moral.

O uso dessas denominações reflete o preconceito social e o forte estigma presente na sociedade em relação aos usuários de crack, remetendo à ideia de que o próprio sujeito deve ser evitado e enfrentado e não somente a droga em si.

Segundo Goffman (2004), atribui-se esta identidade social a eles estabelecendo meios de categorização. Isso evidencia algo extraordinário ou mau, ou seja, anormal. Os próprios sujeitos sentem-se inseguros em relação à maneira à qual os "normais" o identificam. O termo "estigma” será utilizado devido aos atributos bastante depreciativos que encontramos nas reportagens. Além disso, um dos passos decisivos no processo de construção de um padrão desviante, para Becker (2008), é a experiência de ser apanhado e rotulado publicamente de desviante. Nesse caso, a mídia influencia estas experiências, tornando público o consumo desta substância. O estereótipo do usuário de crack retrata uma pessoa que viola a moralidade.

Já Fiorin (1988) descreve que o discurso transmitido contém em si a visão de mundo que veicula um sistema de valores, isto é, estereótipos dos comportamentos humanos que, Nessa situação, são valorizados negativamente. A sociedade usa tais termos para identificar os usuários de crack e estes estereótipos entranham-se de tal modo na consciência que acabam por ser considerados naturais. Os termos que apareceram têm conteúdo regado de preconceitos, aversões, hostilidades e só existem na linguagem porque representa a condensação de uma prática social, a exclusão.

A forma que os meios de comunicação veiculam a imagem dos usuários de crack, apontando-os como perigosos e associando-os à criminalidade, além de ilustrar um cenário de guerra, em meio ao lixo e à degradação humana, representa realidades no imaginário do leitor, transmitindo um perigo aparente. 
As regiões são identificadas como fachada das representações. A cracolândia é um exemplo disso. Ela representa a função à qual o local é utilizado no momento em que as pessoas o frequentam (GOFFMAN, 1985). Dessa forma, o ato de frequentá-la já simboliza algo, os comportamentos dos indivíduos nesta região já são esperados. Assim é construída a imagem do local e também dos frequentadores dele. Isso formaliza a ideia preexistente, transforma-os em um problema da psiquiatria e da polícia, inserindo-os em um processo de medicalização ou em ações de repressão. Desse modo, Foucault (2008) corrobora a questão da normalização e do manejo dos anormais. Os usuários de crack fogem do padrão normal estabelecido e a busca por torná-los aptos a esse modelo perpassa a psiquiatria.

Quanto aos locais de consumo, foram descritos como "submundo" (Folha de SP, 01/05/15), "lixo" (ibibem, 16/04/15; 06/01/12), “imundice" (ibidem, 16/05/14), "perebolandia" (ibidem, 11/03/14), "zoológico humano" (ibidem, 16/05/14), "mundo marginal itinerante" (ibidem, 11/12/12), "maldição do centro, centro nervoso" (ibidem, 15/11/11), "mercado de pulgas" (ibidem, 01/07/12). Nestes locais era possível encontrar "nuvens de mosquito, ratos, baratas, cheiro de urina e fezes" (ibidem, 06/01/12).

Estas cenas têm recebido diversas denominações, fornecendo termos para descrever representações que têm legitimidade perante a sociedade (GOFFMAN, 1985). Nesse caso, usar crack é sinônimo de morar na rua em condições precárias e esta conduta é incompatível com os valores atualmente concebidos.

Estas falas apresentadas pelos discursos das reportagens reproduzem com nitidez os elementos da ideologia da higiene. Esta ideologia existe no Brasil desde a época dos cortiços, em meados de 1870, quando as autoridades se uniram à população para despejar os indesejáveis das cidades (CHALHOUB, 1996). Dessa forma, a questão higienista de enfrentamento do crack fica literalmente evidente nos textos.

A grande maioria dos textos retrata a realidade da cracolândia no centro de SP, mas, em contrapartida, os resultados da pesquisa em nível nacional apontam que o maior número de usuários foi encontrado na região Nordeste (Carta Capital, 19/09/13; Folha de SP, 19/0913). Esse dado mostra a direção que é dada ao problema e o modelo político que é imposto de forma subliminar para uma questão de saúde pública, que de certa forma fica transformada para o individual, mostrando o fracasso do sujeito sem o considerar como um ser social. 
O usuário é citado como perigoso e irrecuperável (Folha de SP, 19/02/13), tornando quase impossível superar o estigma nele depositado. Membros com estigmas semelhantes tendem a se reunir em grupos, pois ali são considerados normais. Neste meio não precisam se envergonhar nem se autocontrolar, pois sabem que serão comuns aos outros que ali habitam (GOFFMAN, 2004). Como não são aceitos pela maioria, faz sentido que os usuários se reúnam, contribuindo para a perpetuação da segregação e do estigma existente.

Estigma é um atributo profundamente depreciativo e denomina indivíduos que se afastam do normal, pois não atingem as expectativas e previsões impostas pela sociedade (ibidem, 2004). O estigma existente nesses usuários pode gerar preconceito e influenciar de forma negativa suas opções de vida, bem como acesso ao lazer, saúde, educação, emprego. Isso cria um círculo vicioso no qual os que já vivem em situação de vulnerabilidade continuem a ser invisíveis perante a sociedade.

A mídia, nesse caso, possui controle do cenário determinando a informação que o público vai adquirir. Tendo acesso a ela, os fatos podem ser manipulados, pelas impressões que são construídas (GOFFMAN, 1985). Nesse sentido, Arenari e Dutra (2016) ponderam a questão da construção da identidade social dos usuários de crack, ou seja, como atributos, capacidades, incapacidades, estigmas são socialmente atribuídos e incorporados por eles em seus percursos biográficos em diferentes esferas, organizações e relações sociais.

Além da incorporação do próprio usuário, a mídia também é capaz de reproduzir isso, pela criação e manutenção de um perfil negativo destes indivíduos no imaginário da população por meio de seus discursos. Estes conceitos provêm da ideologia da classe dominante sobre o tema, reproduzindo o que esta classe pensa e desconstruindo os avanços conquistados pela Reforma Psiquiátrica.

\section{Categoria 3: O usuário de crack como doente}

Esse tipo de representação do usuário de crack como um doente e a dependência de crack descrita como uma doença crônica, progressiva e fatal, que deve preferencialmente ser tratada em hospitais dentro de um modelo biomédico, é bastante difundida nas reportagens pesquisadas (Carta Capital, 10/05/13; Folha de $S P, 11 / 12 / 12 ; 23 / 10 / 12)$.

Os usuários não aderem às normas sociais referentes à conduta estabelecida pela sociedade e são descritos como desviantes. Segundo Goffman (2004), são uma negação coletiva da ordem social. 
Os termos utilizados pelas reportagens para denominar a dependência química ao crack foram: "vício", "tragédia humana", "escravidão", "degradação humana", "fantasma", "câncer" e "flagelo" (CARTA CAPITAL, 2015; CAROS AMIGOS, 2015; FOLHA DE SP, 2015).

Essas citaçōes caracterizam a dependência química não somente como doença, mas também mostram uma direção que pode ser entendida enquanto culpa de caráter moral, segundo Goffman (2004). Dessa maneira, ampliam e reforçam mitos e preconceitos sobre as pessoas que consomem drogas. Ao utilizar o termo "Epidemia", parece que o que está em pauta não é a forma como o aumento do consumo é trazido e sim a associação do usuário de crack a um sujeito doente que necessita intervenção médica, o que ficou transparente nos discursos.

Considerando que epidemia é definida enquanto uma alteração do estado de saúde-doença de uma população de forma crescente, inesperada e descontrolada dos casos em relação ao esperado para aquela doença, superando o que habitualmente fora estabelecido para ela, segundo Rouquayrol (2009), é um forte equívoco a utilização deste termo para a situação do uso de crack no Brasil, tanto pela falta de uma série histórica que contemple dados epidemiológicos, quanto por denominar todos os usuários como doentes.

Essa situação aponta para Foucault (2008), quando ele refere que as relações entre um mal e um lugar já foram definidas e descritas desde os séculos XII e XIII. Isso nos remete à maneira como os usuários de crack são descritos, ou seja, suas condições precárias de abuso da substância em meio a locais de riqueza, espalhados nas ruas da cidade, tornando visível o indesejável: a dependência química. Nesse sentido, a doença justifica as práticas de recolhimento, limpeza e internação compulsória na região da cracolândia.

Essa forma de entender as doenças mentais foi firmada a partir da segunda metade do século XIX, quando iniciou um novo modo de abordagem. Faz parte de uma mudança epistemológica no campo da psiquiatria que começou a unir um conjunto cada vez mais amplo de condutas e comportamentos e classificálos como patologias psíquicas que demandassem intervençóes terapêuticas (CAPONI, 2012). O crack atualmente está inserido nesse contexto e faz parte de um discurso da prática médica.

Esta analogia médica do usuário de crack ao doente mental dá origem ao comportamento desviante, segundo Becker (2008). Nesse sentido, tenta-se 
desvelar a causa de um comportamento indesejado e a medicina tenta descobrir a etiologia das doenças reafirmando a ideia de doença.

Além disso, há um envolvimento de forças de controle social (BECKER, 2008). Associar o usuário a doente nesse contexto de epidemia justifica a manutenção deste status inconveniente e imoral do uso de algumas drogas. Também deixa implícito na interação entre usuários e psiquiatras que os especialistas no assunto é que sabem o que estão fazendo. De qualquer modo, a dependência de crack muito mais que doença representa uma ameaça social nessa conjuntura.

\section{Categoria 4: Opinião de moradores e leitores sobre o sujeito usuário de crack}

A opinião de moradores e leitores sobre o sujeito usuário de crack é outra categoria destacada na nossa pesquisa que mostra a forma como pensam e se manifestam os moradores da região da cracolândia, alguns leitores e o público em geral perante o tema.

As opiniōes retratam os usuários como pessoas perigosas e creem que sua presença "atrapalha a prosperidade do bairro" (Folha de SP, 16/04/15), a "segurança das pessoas" (ibidem, 16/05/14) e o "direito de ir e vir" (ibidem, 16/10/10). Os moradores sentem-se "desamparados" (ibidem, 03/01/14) e com menos direitos que os usuários que recebem alimentação e moradia gratuitamente do Estado, demonstrando a preocupação individual diante de problemas de ordem coletiva.

Eles apontam que não querem a "miséria humana" sentada à sua calçada e sugerem que os "defensores de direitos humanos os levem para casa" (ibidem, 12/01/12). Creem que manter projetos e usuários no bairro irá "destruir a regiāo" (ibidem, 15/04/15), pois são pessoas que "degradam a imagem do centro da cidade" (ibidem, 11 dezembro 2012), e reforçam que o hospital psiquiátrico seria uma opção de destino para estas pessoas.

O hospital, nesse caso, não só tem a função de tratamento, como habitualmenteé citado, mas principalmente de modelar e sujeitar as subjetividades ali "confinadas". Estabelece relações de tratamento, vigilância, obediência e segregação, com a preocupação maior de manter a sociedade em segurança (GOFFMAN, 2013).

Além disso, os moradores e comerciantes da região aplicam sua moralidade e os seus ideais de vida aos outros. Para Becker (2008) para um ato ser desviante ou não, depende das reações de outras pessoas ao comportamento e o juízo que 
fazem dele. Não é uma qualidade que reside no próprio comportamento e sim

a interação entre a pessoa que comete o ato e àquelas que reagem a ele, ou seja, ao conceber os usuários como problema o transforma nisto. Além disso, ao transmitir estas opiniōes, a mídia reforça ao público a certeza de suas crenças, tornando seu espetáculo aceitável e verdadeiro (GOFFMAN, 1985).

Quando ocorrem operaçôes policiais e de limpeza dos locais de consumo da droga, comerciantes e moradores elogiam a conduta e "comemoram o aumento no movimento do comércio" e até da "qualidade do ar" (Folha de SP, 06/01/12), reforçando a ideologia da higiene, que já existe desde o século XIX e que perdura no Brasil desde a época dos cortiços, por meio do combate às "classes pobres" e "classes perigosas", quando as autoridades se uniam à população para despejar os indesejáveis das cidades (CHALHOUB, 1996).

Além desta ideologia, os desvios de Becker (2008) também são representados nessas situações. Seu grau depende de quem comete e de quem é prejudicado por ele. Por exemplo, no caso das drogas, a lei é aplicada diferentemente ao abuso de ecstasy em festas de classe alta e ao uso de crack na cracolândia, pois neste segundo caso os moradores sentem-se prejudicados pela presença indesejável de usuários de crack em seu entorno.

Os comentários encontrados têm forte apelo emocional, replicam opiniões como verdades com pouco ou praticamente nenhum aprofundamento teórico, técnico ou científico, reproduzindo, dessa forma, um perfil negativo destes indivíduos.

\section{Categoria 5: Opinião de políticos, profissionais de saúde, religiosos e outros profissionais sobre usuários de crack}

Outro dado que contribui para a formação do perfil do usuário é traduzida pela opinião de políticos, profissionais de saúde, religiosos e outros profissionais sobre o tema.

Esses agentes apareceram nos textos repetidas vezes, alguns expondo opiniōes diversas na mesma reportagem. Com isso, observamos que o discurso perpassa a questão midiática e adentra campos distintos. Os que apareceram mais fortemente representados foram o campo médico, político, jurídico e o social. Isso mostra que estes profissionais são formadores de opinião pública, pois transferem seus conhecimentos e experiências por meio da mídia. 
Para Goffmann (1985), os especialistas formulam elementos concretos de sua exposição verbal, argumentando e demonstrando sua posição intelectual. $\mathrm{Na}$ maioria das vezes, são pessoas distantes socialmente dos serviços que prestam, ou seja, não são membros da mesma equipe, não compartilham dos riscos, culpa ou insatisfações, não vivem na pele a realidade daqueles a quem concedem seus conhecimentos.

Becker (2008) corrobora esta afirmação ao dizer que os criadores destes discursos, normalmente, estão em níveis superiores da estrutura social e fazem uso de seu patamar para legitimar sua posição moral. Acrescenta que estes grupos exercem seu controle e poder de maneira disfarçada, baseados no monitoramento, formação e manipulação de rótulos a estas pessoas.

A opinião de psiquiatras e médicos é bastante exaltada nas reportagens, insinuando autoridade sobre o tema e colocando-se acima da razão perante os usuários, que não teriam razão nenhuma para o consumo, sem considerar os fatores etiológicos que podem contribuir para essa situação. Esta ideologia psiquiátrica se torna cada vez mais aceitável e reproduz a questão do crack como doença e os usuários como doentes, dando a entender aos leitores que a internação é o principal meio e o mais adequado de enfrentamento da situação. Isso vem frequentemente associado à desqualificação da rede de atenção disponível no SUS e das práticas de RD como se fossem ineficazes e insuficientes em todos os casos.

Outro aspecto importante a ser discutido é que estes profissionais parecem fornecer opiniōes ou diagnósticos inquestionáveis, devido a seu alto grau de instrução e qualificações, reforçando ainda mais as suas ideias e disseminando esse saber a outros e à população.

Também existe uma discordância de opiniōes entre o paradigma psiquiátrico e as propostas da Reforma Psiquiátrica no que diz respeito às opções de tratamento propostas por especialistas, pois ora afirmam que os usuários são doentes e devem ser tratados em hospitais e não em hotéis, ora dizem que o caminho mais adequado é cuidar do indivíduo no contexto que ele aceite, sendo tratado e respeitado em seu ambiente, defendendo as práticas de Redução de Danos (FOLHA DE SP, 2015). Estes atores fazem uso de termos padronizados de comunicação, elaborando meios de transmitir mensagens verbais, protegendo a impressão projetada de modo que não prejudique a ilusão que está sendo criada para sua plateia (GOFFMAN, 1985). 
A linguagem utilizada e os assuntos trazidos pelos especialistas criam e reforçam a formação de verdades, segundo Foucault (2014). A verdade, dessa maneira, é valorizada e reproduzida por esta instituição da forma como o saber é aplicado, ou seja, os leitores tomam como verdades aquilo que leem, sem questionar ou relativizar o que é divulgado. Isso fica evidente quando a mídia faz uso da ciência para disfarçar a moral presente em seu discurso.

Ou seja, quanto mais alta é a posição do informador, maior credibilidade tem a notícia perante o público (FOUCAULT, 2014), mais facilmente é naturalizada e aceita como verdade. Então, usar as palavras "psiquiatra", "médico", "pesquisador", "coordenador", "secretário de saúde" ou de "segurança pública", "promotor de justiça”, entre outros, confere à informação maior valor e confiabilidade perante os que a recebem.

A aproximação entre as equipes e o apoio social entre os membros podem ter maior valor terapêutico que sua distância (GOFFMAN, 1985). Isso faz com que os menos favorecidos aceitem melhor as ideias dos mais bem colocados socialmente. Nesse caso, os Consultórios de Rua, projetos de RD, CAPS, onde existe uma interação entre profissionais e usuários dentro dos locais de consumo, podem ser mais efetivos, pois estão mais próximos da realidade estudada.

Esta categoria demonstrou, de maneira geral, que existem opiniōes negativas quanto ao perfil usuários de crack feitas por estes profissionais nas reportagens analisadas. Os especialistas sugerem ao leitor que os usuários não têm direito a usar a droga em segurança e muito menos a locais adequados de moradia se não comprovarem abstinência. Ou seja, propõem este meio como condiçãoo para o cuidado.

\section{Considerações finais}

Esta pesquisa teve como objetivo analisar o perfil dos usuários de crack por meio de reportagens de um jornal e de duas revistas de circulação nacional. Ela nos permitiu identificar que a apropriação do discurso constrói no senso comum uma imagem negativa dos usuários de crack, permeado por preconceitos e estigmas. Isso não foi um fato isolado nas reportagens estudadas, e sim uma confirmação do processo histórico de exclusão dos portadores de doença mental, negros pobres, homossexuais, entre outras classes desfavorecidas, reproduzindo a ideologia da classe dominante. Justifica a centralização do poder na instituiçãoo 
hospitalar e no modelo biomédico, trazendo à tona que o próprio sujeito deve ser evitado e enfrentado e não somente a droga em si.

A análise foi possível com as contribuições dos autores utilizados. Devido à amplitude e complexidade do tema, ela foi direcionada ao desenrolar da transformação da loucura em doença mental, à constituição da prática psiquiátrica, à definição dos estigmas e preconceitos existentes, à forma como os desvios sociais são criados em nossa sociedade, bem como à abordagem da formação ideológica e discursiva da mídia e sua transmissão de informaçôes sobre os usuários de crack.

O perfil identificado está inserido no contexto da biopolítica das populações de risco, que teve início a partir do final do século XIX e início do século XX. Junto, surgem novas estratégias de intervenção, terapêuticas e um discurso higiênico. Com esta forma de controlar as populaçôes, o objetivo prioritário é antecipar os perigos. "É em nome da saúde de todos, da vitalidade da espécie, do controle das doenças e da antecipação dos perigos que a biopolítica pode multiplicar os espaços médicos de intervenção social" (CAPONI, 2012, p. 24).

A mídia, representada neste estudo pelas três fontes pesquisadas, tornase um potente aparelho ideológico e formador de opinião. Ela influencia a avaliação moral que fazemos dos usuários de crack com a forma que transmite as informações sobre os aspectos que circundam o usuário de crack na sua pauta. Isso mostra claramente que existem formaçôes discursivas que colaboram para a construção de verdades em nosso meio.

Dessa forma, fica evidente que ela desconsidera o que é preconizado na legislação brasileira e em toda a Rede de Atenção Psicossocial (RAPS) até então instituída, principalmente o jornal Folha de São Paulo, que é um veículo diário e, portanto, com grande impacto coletivo, além da revista Carta Capital, que é semanal, demonstrando uma forma de controle e manutenção da ideologia biomédica perante a população, com informaçôes equivocadas quanto aos ideais de RP.

Em contrapartida, as estratégias pautadas na RP estiveram pouco presente no corpus, e apareceram principalmente na revista Caros Amigos. Também surgiram nas demais fontes, mas, na maioria das ocasiōes, acompanhadas de críticas quanto ao número reduzido de unidades, baixa efetividade e resolutividade, o que torna aceitável aos leitores a ideologia biomédica de cuidado como a única alternativa viável. 
A contribuição desta pesquisa visa desnaturalizar o processo existente, tentando quebrar o paradigma de afastar as pessoas em sofrimento psíquico, nesse caso, os usuários de crack, e identificando com um novo olhar a informação que nos é transmitida pelos meios de comunicação.

A análise das reportagens demonstrou a complexidade do fenômeno estudado, e temos consciência de que a discussão não foi esgotada com a época consultada e com a metodologia escolhida para o estudo. Mas podemos afirmar que o conhecimento veiculado por reportagens de jornais de circulação nacional forma opiniōes sobre os usuários de crack e parece vir em contramão à Reforma Psiquiátrica Brasileira. ${ }^{1}$

\section{Referências}

ARENARI, B.; DUTRA, R. A construção social da condição de pessoa: premissas para romper o círculo vicioso de exclusão e uso problemático do crack. In: SOUZA, J. (Org.). Crack e exclusão social. Brasília: Ministério da Justiça e Cidadania, Secretaria Nacional de Política sobre Drogas, 2016. Cap. 8.

BECKER, H.S. Outsiders: Estudos da sociologia do desvio. Trad. Maria Luiza X. de Borges; revisão técnica de Karina Kuschnir. Rio de Janeiro: Editora Jorge Zahar, 2008.

BRASIL. Presidência da República. Casa Civil. Subchefia para Assuntos Jurídicos. LEI $n^{\circ}$ 10.216, DE 6 DE ABRIL DE 2001. Dispõe sobre a proteção e os direitos das pessoas portadoras de transtornos mentais e redireciona o modelo assistencial em saúde mental. Disponível em: $<$ http://www.planalto.gov.br/ccivil_03/leis/leis_2001/110216.htm>. Acesso em: 22 jan. 2014.

- Sistema Único de Saúde. Conselho Nacional de Saúde. Relatório final da III Conferência Nacional de Saúde Mental. Brasília: Ministério da Saúde, 2002.

Sistema Único de Saúde. Conselho Nacional de Saúde. Relatório final da IV Conferência Nacional de Saúde Mental. Brasília: Ministério da Saúde, 2010.

CAPONI, S. Loucos e Degenerados: uma genealogia da psiquiatria ampliada. Rio de Janeiro: Fiocruz, 2012.

CAROS AMIGOS. Crack: Para além dos slogans do Plano de Enfrentamento: Educador analisa abordagem política e de saúde pública no combate à droga. São Paulo, 03 jan. 2012. Disponível em: <http://www.carosamigos.com.br>. Acesso em: 20 jan. 2016.

Disponível em: <http://www.carosamigos.com.br/index.php/fale-conosco/ história>. Acesso em: 05 jun. 2015.

. Entrevista Dartiu Xavier: "A internação compulsória é sistema de isolamento social, não de tratamento". São Paulo, 07 jan. 2013. Disponível em: <http://www.carosamigos. com.br>. Acesso em: 20 jan. 2016. 
. Internação compulsória: tratamento ou isolamento social? São Paulo, 11 jan. 2013. Disponível em: <http://www.carosamigos.com.br> Acesso em: 20 jan. 2016.

. Plano de enfrentamento ao crack divide especialistas. São Paulo, 20 mar. 2012. Disponível em: <http://www.carosamigos.com.br>. Acesso em: 20 jan. 2016.

CARTA CAPITAL. A vida em primeiro lugar. São Paulo, 10 jul. 2013. Disponível em: <http://www.cartacapital.com.br>. Acesso em: 01 fev. 2016.

Ação da polícia parte de visão higienista”. São Paulo, 06 jan. 2012. Disponível em: <http://www.cartacapital.com.br>. Acesso em: 01 fev. 2016.

. Crack, uma epidemia devastadora. São Paulo, 30 jul. 2010. Disponível em: <http://www.cartacapital.com.br>. Acesso em: 01 fev. 2016.

. Craqueiros cercados. São Paulo, 16 maio 2014. Disponível em: <http://www. cartacapital.com.br>. Acesso em: 01 fev. 2016.

. Disponível em: <http://www.cartacapital.com.br/editora/cartacapital>. Acesso em: 05 jun. 2015.

. Governo federal passa a tratar crack como problema social. São Paulo, 01 mar. 2015. Disponível em: <http://www.cartacapital.com.br>. Acesso em: 01 fev. 2016.

Número de usuários de crack chega a 370 mil nas capitais. São Paulo, 19 set. 2013. Disponível em: <http://www.cartacapital.com.br>. Acesso em: 01 fev. 2016.

. Operação da prefeitura na Cracolândia completa um mês. São Paulo, 14 fev. 2014. Disponível em: <http://www.cartacapital.com.br>. Acesso em: 01 fev. 2016.

CHAlHOUB, S. Cidade febril: Cortiços e epidemias na Corte imperial. São Paulo: Companhia das Letras, 1996.

FIORIN, J.L. Linguagem e Ideologia. São Paulo: Ática, 1988.

FOLHA DE SÃO PAULO. "Não funcionou”, diz homem que foi internado à força. São Paulo, 22 jan. 2013. Disponível em: <http://wwwl.folha.uol.com.br>. Acesso em: 15 abr. 2015.

. "Pregão do crack" atrai cerca de 300 usuários no centro de SP. São Paulo, 06 jan. 2012. Disponível em: <http://www1.folha.uol.com.br>. Acesso em: 15 abr. 2015.

38,7\% dos usuários de crack das capitais do país estão no Nordeste. São Paulo, 19 set. 2013. Disponível em: <http://wwwl.folha.uol.com.br>. Acesso em: 15 abr. 2015.

A banalização de medidas autoritárias. São Paulo, 19 fev. 2013. Disponível em: <http://wwwl.folha.uol.com.br>. Acesso em: 15 abr. 2015.

. A política e o resto. São Paulo, 19 jan. 2013. Disponível em: <http://www1.folha. uol.com.br>. Acesso em: 15 abr. 2015.

Bebês abandonados por adolescentes viciadas em crack preocupam autoridades do Rio. São Paulo, 22 set. 2013. Disponível em: <http://wwwl.folha.uol.com.br>. Acesso em: 15 abr. 2015. 
. Comerciantes da região da cracolândia aprovam operação em SP. São Paulo, 06

jan. 2012. Disponível em: <http://wwwl.folha.uol.com.br>. Acesso em: 15 abr. 2015.

. Consumo de crack no Brasil não é epidemia, diz ministro da Saúde. São Paulo, 05 out. 2011. Disponível em: <http://wwwl.folha.uol.com.br>. Acesso em: 15 abr. 2015.

. Crack muda trajeto de ônibus em São Paulo. São Paulo, 15 nov. 2011 Disponível em: <http://www1.folha.uol.com.br>. Acesso em: 15 abr. 2015.

. Crack resiste e com ele sujeira se alastra pelo centro de SP. São Paulo, 30 set. 2012. Disponível em: <http://wwwl.folha.uol.com.br>. Acesso em: 15 abr. 2015.

. De volta ao crack. São Paulo, 09 fev. 2013. Disponível em: <http://www1.folha. uol.com.br>. Acesso em: 15 abr. 2015.

. Diário de uma quase sobrevivente da cracolândia: "Perda total". São Paulo, 11 mar. 2014. Disponível em: <http://wwwl.folha.uol.com.br>. Acesso em: 15 abr. 2015.

. Especialistas da ONU e OMS criticam internação compulsória de viciado. São Paulo, 06 fev. 2013. Disponível em: <http://wwwl.folha.uol.com.br>. Acesso em: 15 abr. 2015.

. Exilados da cracolândia vagam pelo centro de São Paulo. São Paulo, 09 ago. 2009. Disponível em: <http://www1.folha.uol.com.br/institucional/missao.shtml>. Acesso 10 jun. 2015.

. Hotel em Campos Elíseos será "filial” da cracolândia, diz moradora do bairro. São Paulo, 16 abr. 2015. Disponível em: <http://www1.folha.uol.com.br>. Acesso em: 15 abr. 2015.

. Leitor critica protetores de usuários de crack em São Paulo. São Paulo, 12 jan. 2012. Disponível em: <http://www1.folha.uol.com.br>. Acesso em: 15 abr. 2015.

. Leitora rebate leitor que criticou protetores de usuários de crack em SP. São Paulo, 12 jan. 2012. Disponível em: <http://wwwl.folha.uol.com.br>. Acesso em: 15 abr. 2015.

. Leitores comentam instalação de "cercadinho" para usuários de crack. São Paulo, 16 maio 2014. Disponível em: <http://wwwl.folha.uol.com.br>. Acesso em: 15 abr. 2015.

. Lojista afirma que planeja empregar usuários de droga em SP. São Paulo, 18 maio 2014. Disponível em: <http://www1.folha.uol.com.br>. Acesso em: 15 abr. 2015.

- Maioria dos usuários da cracolândia nunca recebeu tratamento, diz pesquisa. São Paulo, 01 ago. 2012. Disponível em: <http://wwwl.folha.uol.com.br>. Acesso em: 15 abr. 2015.

. Mais de 1,2 mil crianças e adolescentes viciadas em crack vivem em SP. São Paulo, 10 mar. 2013. Disponível em: <http://www1.folha.uol.com.br>. Acesso em: 15 abr. 2015.

. Moradores do centro de SP se unem para exigir o fim da cracolândia. São Paulo, 03 jan. 2014. Disponível em: <http://wwwl.folha.uol.com.br>. Acesso em: 15 abr. 2015. 
Moradores vão à Justiça contra hotel para usuários de crack no centro de SP. São Paulo, 15 abr. 2015. Disponível em: <http://wwwl.folha.uol.com.br>. Acesso em: 15 abr. 2015.

. Obra parada da Nova Luz, em SP, vira abrigo para centenas de usuários de crack. São Paulo, 14 set. 2010. Disponível em: <http://wwwl.folha.uol.com.br>. Acesso em: 15 abr. 2015.

. Operação na cracolândia apenas espalhou usuários, critica leitora. São Paulo, 11 dez. 2012. Disponível em: <http://wwwl.folha.uol.com.br>. Acesso em: 15 abr. 2015.

. Pedestres formam comboio para evitar usuários de crack em SP. São Paulo, 16 out. 2010. Disponível em: <http://wwwl.folha.uol.com.br>. Acesso em: 15 abr. 2015.

. Pesquisa da Fiocruz indica que 20\% dos usuários das cracolândias são mulheres. São Paulo, 08 set. 2014. Disponível em: <http://www1.folha.uol.com.br>. Acesso em: 15 abr. 2015.

. Petistas defendem ação de Haddad na cracolândia; vereador rebate PSDB. São Paulo, 01 maio 2015. Disponível em: <http://wwwl.folha.uol.com.br>. Acesso em: 15 abr. 2015.

. Rio vai criar até 700 vagas para abrigar dependentes de crack. São Paulo, 23 out. 2012. Disponível em: <http://www1.folha.uol.com.br>. Acesso em: 15 abr. 2015.

. Ruínas de cortiço revelam cotidiano da cracolândia; veja galeria. São Paulo, 06 jan. 2012. Disponível em: <http://wwwl.folha.uol.com.br>. Acesso em: 15 abr. 2015.

. Seis meses após início de ação da polícia, cracolândia persiste. São Paulo, 01 jul. 2012. Disponível em: <http://www1.folha.uol.com.br>. Acesso em: 15 abr. 2015.

_. Um ano depois da ocupação da cracolândia pela PM, tráfico persiste. São Paulo, 03 jan. 2013. Disponível em: <http://www1.folha.uol.com.br>. Acesso em: 15 abr. 2015.

. Usuários de drogas da cracolândia seguem código de conduta. São Paulo, 19 jan. 2014. Disponível em: <http://www1.folha.uol.com.br>. Acesso em: 15 abr. 2015.

- Viciado da cracolândia é lanterna entre os excluídos. São Paulo, 15/01/12. Disponível em: <http://www1.folha.uol.com.br>. Acesso em: 15 abr. 2015.

FOUCAULT, M. Segurança, Território e População. Curso ministrado no Collège de France, aula de 11 de janeiro de 1978. São Paulo: Editora Martins Fontes, 2008.

História da loucura na Idade Clássica. Trad. José Teixeira Coelho Neto. São Paulo: Ed. Perspectiva, 2010.

. Microfísica do Poder. 28. ed. Rio de Janeiro: Editora Paz e Terra, 2014.

GOFFMAN, E. A Representação do eu na vida cotidiana. Trad. Maria Célia Santos Raposo. Petrópolis: Vozes, 1985.

Estigma. Notas sobre a manipulação da identidade deteriorada (1981). Trad. Mathias Lambert, Digitalização, 2004. 
Paulo: Ed. Perspectiva, 2013.

GORGULHO, M. A influência da mídia na realidade brasileira do fenômeno das substâncias psicoativa. In: Panorama Atual de Drogas e Dependências. São Paulo: Ed Abeneu, 2006.

LOPES, E.P. O tratamento ao usuário de crack nas páginas policiais dos jornais brasileiros. RECIIS - R. Eletr. de Com. Inf. Inov. Saúde. Rio de Janeiro, v. 7, n. 3, set. 2013. Disponível em: <www.reciis.icict.fiocruz.br>. Acesso em: 1 abr. 2016.

MESSAS, G. et al. Por uma psicopatossociologia das experiências dos usuários de drogas nas cracolândias/cenas de uso do Brasil. In: SOUZA, J. (Org.). Crack e exclusão social. Brasília: Ministério da Justiça e Cidadania, Secretaria Nacional de Política sobre Drogas, 2016. Cap. 7. MORAES, R.; GALIAZZI, M. do C. Análise Textual Discursiva. Ijuí: Ed. Unijuí, 2007.

OLIVEIRA, L.R.; NAPPO, A.S. Caracterização da cultura de crack na cidade de São Paulo: padrão de uso controlado. Revista de Saúde Pública, v. 42, n. 4, p. 664-671, 2008.

PORTO, M.S.G. Mídia, segurança pública e representações sociais. Tempo Social, Revista de Sociologia da USP, v. 21. Disponível em: <www.scielo.br/pdf/ts/v21n2/v21n2a10.pdf>. Acesso em: 25 mar. 2016.

ROUQUAYROL, M.Z. Contribuição da Epidemiologia. In: CAMPOS, G. W. de S. et al. (Orgs.). Tratado de Saúde Coletiva. Rio de Janeiro: Ed. Fiocruz; São Paulo: Ed Hucitec, 2009. Cap. 11.

THOMPSOM, John B. A Mídia e a modernidade: uma teoria social da mídia. Petrópolis: Editora Vozes, 2002.

\section{Nota}

${ }^{1}$ D.F. Zanotto participou da pesquisa documental, análise dos dados e da construção do artigo. F.B. Assis participou da análise de dados e revisão do artigo. Esta pesquisa não contou com financiamento e é resultado de um dos artigos da tese de doutorado defendida em 2016, não existindo conflito de interesses. 


\section{Abstract}

\section{Profile of crack users in the Brazilian media: analysis of a national newspaper and two magazines}

This article is a documentary research with qualitative approach, resulting from a doctoral thesis, which sought to analyze the profile of users of crack presented by newspaper reports and two national edition magazines in the last five years. The material found was submitted to discursive textual analysis. In order to access the study object, our theoretical base was based on Michel Foucault, Erwin Goffman, Howard Becker and John Thompson, seeking to denature the ways in which discourses about crack users are placed by the media. The results showed that the discourse conveyed by the media studied builds a negative profile on the crack user, permeated by prejudice and stigma. The reports are sensationalist and hygienist, emphasizing the confrontation with the users and not only the drug itself. It concludes that the presented discourse is capable of materializing the representations of the ruling class over crack users and of reflecting on the way in which society lives with them. One considers dominant class the one represented by the biomedical model of mental health care.

> Keywords: crack cocaine users; mass media; Brazilian Psyquiatric Reform. 